Lívia de Rezende Cardoso

Universidade Federal de Sergipe, Aracaju, Sergipe, Brasil

\title{
Relações de gênero, ciência e tecnologia no currículo de filmes de animação
}

Resumo: Invenções, tecnologias, experimentos, livros e ferramentas são elementos que fazem parte das tramas de Tá chovendo hambúrguer l e ll. O presente artigo tem o objetivo de analisar as relações de gênero em tais filmes de animação que apresentam como pano de fundo invenções e verdades científicas e tecnológicas, permeadas por demandas generificadas. Desse modo, argumento que, nos filmes analisados, são produzidas posições de sujeito diferenciadas para homens e mulheres por meio do discurso científico-tecnológico. Nos artefatos culturais analisados, alguns sujeitos são próprios do fazer científico, do racional, da inventividade tecnológica. Outros possuem papel secundário, coadjuvante e de assistência. Isso contribui para a produção de sujeitos generificados na ciência. Assim, em meio a hambúrgueres, queijos e molhos, chovem discursos e demandas para o governo daqueles/as que os assistem. Palavras-chave: Relações de Gênero; Discurso Científico; Subjetivação.

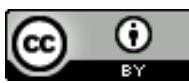

Esta obra está sob licença Creative Commons.

\footnotetext{
1 Distribuídos pela Sony Pictures, Tá chovendo hambúrguer I e II, lançados em 2009 e 2013, respectivamente, tiveram, juntos, uma bilheteria de mais de 3,8 milhões de ingressos no Brasil.
}

\section{Introdução}

Invenções, tecnologias, experimentos, livros e ferramentas são elementos que fazem parte do mundo de Flint Lockwood's desde tenra idade. Incentivado por sua mãe a persistir em tal carreira, o garoto cresce vestindo um jaleco branco e perseguindo o sonho de se tornar o maior dos inventores. Nesse cenário das tramas de Tá chovendo hambúrguer l e II,' é possível verificar o já adulto Flint produzir aquilo que salvaria a humanidade: uma máquina que transforma água em comida! Em meio a coloridas e divertidas confusões resultantes da invenção, muitos saberes em torno das relações de gênero e de seus cruzamentos com ciência e tecnologia na sociedade atual são disponibilizados ao público em geral. O conjunto de tais saberes e os sujeitos demandados em meio a relações de poder são aqui analisados. 
Estudos têm buscado analisar artefatos midiáticos, procurando compreender como eles atuam na construção de identidades e subjetividades (GIROUX, 1995; DUARTE, 2002; KINDEL, 2003; FABRIS, 2008; SILVA, PARAÍSO, 2012). A análise aqui empreendida explora a relação entre Estudos Culturais e cinema por compreendê-lo "como um artefato cultural que ensina, educa e produz sujeitos, que está em muitos espaços desdobrando-se em diferentes pedagogias" (PARAísO, 2010, p. 11). Os filmes de animação criam um sistema de significações, constituindo-se como "histórias que nos interpelam de um modo avassalador porque não dispensam o prazer, o sonho e a imaginação" (FABRIS, 2008, p. 118). Isso uma vez que convenções cinematográficas "expressam, de um modo mais ou menos circular, a influência mútua que cinema e sociedade exercem sobre si" (DUARTE, 2002, p. 56). O cinema tornou-se, portanto, uma "instância formativa poderosa, na qual representações de gênero, sexuais, étnicas e de classe eram (e são) reiteradas, legitimadas ou marginalizadas" (LOURO, 2000, p. 423).

Nesse sentido, personagens são "seres de ficção que recriam seres humanos, imaginados ou inspirados na realidade, assim como peças fundamentais que provocarão ou sofrerão as consequências da história" (CÀMERA, 2005, p. 73). Em se tratando dos gêneros infantis, os filmes produzidos têm grande alcance e vinculam diferentes representações e formas de vida (GIROUX, 1995). Na pedagogia do cinema, especialmente a infanto-juvenil, se estaria definindo "o que é bom ou mau, o que é certo ou errado, bem como o que é lícito desejar e o que se deve refutar" (BICCA, 2010, p. 56). Sobre desenhos de animação, Kindel afirma que "crianças os assistem dezenas de vezes, seja nas creches, nas escolas ou mesmo em suas próprias casas e, nesse processo repetitivo são colocadas em destaque determinadas identidades e criam-se padrões de homem, de mulher" (2003, p. 177).

O presente artigo tem, portanto, o objetivo de analisar as relações de gênero em dois filmes de animação que apresentam como pano de fundo invenções e verdades científicotecnológicas. Ao compreender discursos sobre gênero como modo de governo de condutas, considero importante pensálos no cruzamento com os discursos da ciência moderna e suas enunciações salvacionistas e cientificistas. Nesse cruzamento, diferenciadas demandas aos sujeitos entram em conflito a depender da formação discursiva, o que torna o sujeito da ciência um ser conflituoso, híbrido, "que precisa mesclar expressões de feminilidade e de masculinidade, que constantemente foge da biologia e de seu sexo e que se desamarra de normas binárias" (CARDOSO, 2011, p. 56). Investigações que relacionem categorias tais como gênero, sexualidade e ciência já foram apontadas como escassas

464 Estudos Feministas, Florianópolis, 24(2): 463-484, maio-agosto/2016 
no campo da educação científica (CARDOSO, PARAísO, 2014, p. 98). Desse modo, tomo tais filmes como objeto de análises e argumento que, nos filmes de animação analisados, são produzidas posições de sujeito diferenciadas para homens e mulheres através do discurso científico-tecnológico.

Ao realizar as análises, uso o conceito de tecnologia de gênero, explicitado por Teresa de Lauretis (1994), que seria uma espécie de maquinaria, apoiada em diferentes discursos que circulam culturalmente, que cria os sujeitos homem e mulher específicos de uma sociedade. Segundo a autora, é preciso separar gênero da diferença sexual e entendê-lo como produto de variados discursos. Analisá-lo seria apreender técnicas e estratégias por meio das quais o gênero é construído. Desse modo, articulando o que diz Lauretis com as problematizações feitas por Judith Butler sobre sexo e gênero, compreendo gênero, aqui, como "os significados culturais assumidos pelo corpo sexuado" (BUTLER, 2010, p. 24).

Embasada nessas definições, utilizo, nas análises, os conceitos de discurso, posições de sujeito e governo de Michel Foucault. Entendendo o discurso como prática produtiva, busco mostrar como diferentes discursos divulgados nos filmes analisados "remetem uns aos outros, se organizam em uma figura única, entram em convergência com instituições e práticas, e carregam significações que podem ser comuns a toda uma época" (FOUCAULT, 2005, p. 134). Ao atravessar personagens, os discursos convidam sujeitos a posicionaremse por meio de "práticas pelas quais os indivíduos foram levados a prestar atenção a eles próprios" (FOUCAULT, 2006, p. 11). Isso corresponde a investigar os modos de subjetivação que "são todos os processos e as práticas heterogêneas por meio das quais os seres humanos vêm a se relacionar consigo mesmos e com os outros como sujeitos de um certo tipo" (PARAíSO, 2006, p. 101). Nesse processo, estabelece-se o governo de sujeitos que "implica certos modos de educação e de transformação dos indivíduos, na medida em que se trata não somente, evidentemente, de adquirir certas aptidões, mas também de adquirir certas atitudes" (FOUCAULT, 1982 , p. 02). Para tal, processam-se "técnicas do eu e de dominação", que, em seu conjunto, na perspectiva foucaultiana, conforme mostra Paraíso (2007), compõem as "tecnologias de subjetivação".

\section{Com vocês, o cientista maluco!}

"Você já teve a impressão de que era uma pessoa meio diferente, como se tivesse alguma coisa especial para oferecer ao mundo, mas que ninguém percebia? Então, você sabe exatamente como era ser eu!". É desse modo que Flint Lockwood's apresenta-se no início da narrativa de Tá 
chovendo hambúrguer I (TCHI). Cenas de sua infância são logo trazidas, fazendo-o rememorar o quanto era diferenciado das outras crianças. Na mais traumática delas, em que sua nova invenção é apresentada para toda a turma da escola - sapatos sem cadarços feitos com o simples apertar em um spray, mas acidental e inocentemente permanentes-, foi preciso a ajuda de sua mãe para conseguir erguer-se. Relutando contra a imagem negativa do "esquisito" produzida por todos/ as, a Senhora Lockwood's argumenta: "consideravam todos esses inventores esquisitos também. E eles não desistiram". Tais inventores estavam ali, distribuídos em pôsteres pelo quarto do garoto: Nikola Tesla, Albert Einstein e Graham Bell.

É, então, que a mãe o presenteia com um jaleco e ouve dele: "nossa, é um jaleco de verdade, igual ao dos cientistas de verdade". Aproveitando tal entusiasmo do filho, diz: "o mundo precisa de sua originalidade, Flint. Você precisa desenvolvê-la. Eu sei que você vai desenvolver coisas incríveis um dia". O garoto apanha papel e caneta, desenha o seu próprio pôster e coloca-o na parede com a frase: "o melhor inventor de todos". Sucessivas tentativas de invenção sem sucesso são, a partir daí, apresentadas pelo Flint já jovem: "descarecador", "carro voador" e "tradutor de fala de macaco". Mas, quando tudo parecia estar perdido, segundo o próprio Flint, ele "ergue a cabeça e reacende a esperança", tendo sempre em mente a lembrança dos incentivos recebidos da falecida mãe. Uma máquina que transforma água em comida por nano-radiação está prestes a ser criada!

Para isso, ele precisa de nada mais que 17 Gigajoules. E, claro, seria na usina elétrica da cidade de Boca da Maré que ele conseguiria toda essa energia. Flint sai de casa, corre para o laboratório, veste seu jaleco, prepara sua máquina e se dirige à usina. Ao ligar todos os fios e ter a sua máquina voando em alta velocidade, o jovem inventor assiste àquilo que parecia mais um desastre. Assim, após acabar com a festa de inauguração da Sardilândia, promovida pelo prefeito, e causar muita confusão com os/as moradores/as, eis que Flint ouve tudo o que pensam sobre ele: "Flint!", grita o pai, mesmo sem ter certeza, ao perceber que a luz acabara, como se aquela fosse uma prática comum do filho; "esse cara é maluco", afirma uma criança presente; "não quero que ele [seu filho] viva em uma cidade arruinada por suas invenções científicas malucas", repreende o policial.

Diferente, esquisito, persistente, inteligente, original, incrível e maluco seriam características produzidas nos filmes analisados através do discurso científico como sendo inatas ao sujeito infantil-cientista. Seriam, portanto, habilidades que alguns trazem ao nascer. Ou seja, desde tenra idade, seriam manifestadas e precisariam ser estimuladas, desenvolvidas e incentivadas para que se aprimorassem. Seriam atributos 
considerados como indispensáveis e, até, como aquilo que diferencia um cientista de uma pessoa comum. Desde o início da trama de TCHI, há um forte investimento em separar e definir o que seria o grupo de "fazedores de ciência". Isso corresponde, na produção da subjetividade cientista, a fazer perguntar ou perguntar-se "que quer de mim?" (STENGERS, 2000 , p. 166). Tal pergunta "guia comportamentos, produz as normas, técnicas, estratégias, os modos de subjetivação pelos quais os sujeitos da experimentação serão produzidos" (CARDOSO, 2012, p. 42). Assim, quando entra em cena o discurso científico, entra, também, um sujeito por ele acionado.

A subjetividade infantil-cientista, ao ser disponibilizada nesses filmes de animação, convida crianças a se identificarem com tal modo de ser. $\mathrm{E}$, ao serem atravessadas pelos discursos que a compõem, estabelece-se o governo de condutas em torno do que é e do que não é considerado um comportamento de cientistas. Essa demarcação cumpre a função de, por um lado, convidar crianças com certas características a se perceberem como potenciais cientistas. Por outro lado, afasta todas aquelas que não nasceram com tais características e que, por conseguinte, não atendem aos requisitos supostamente necessários a este tipo de sujeito. Tais infantis-cientistas seriam sujeitos diferentes, no sentido de distintos e distantes do restante.

Mostrar cientistas e suas características inerentes também é um investimento de Tá chovendo Hambúrguer II (TCHII). O programa "Magnífico Mundo da Ciência" é apresentado por Chester V, ídolo de Flint, no início dessa trama. Nele, o maior dos cientistas convida as crianças a se encantarem com a ciência. Incentiva, sobretudo, que invenções geniais sejam enviadas à sua equipe da Live Corp Corporations, pois, segundo ele, "suas ideias podem mudar o mundo". Há, em seu programa de ciência, um chamamento para aqueles/as que se identificam com o seu mundo. Isto é, se você possui uma das características próprias aos/às cientistas já divulgadas no primeiro filme e bem explícitas nesse personagem, junte-se a ele!

A identificação entre Flint e seu ídolo é vasta. Chester $\mathrm{V}$, em uma visita ao laboratório de Flint, mostra-se surpreendido ao perceber que o laboratório do fã também foi construído nas alturas para se livrar do "bullying" sofrido pelo garoto. Além disso, suas cuecas, criadas aos 3 e aos 5 anos, respectivamente, são elásticas e à prova do "cuecão". Fica evidente, em diversas passagens dos filmes, a exclusão sofrida por eles quando crianças. Flint, por exemplo, não sabia brincar de "boladas de neve" quando a chuva de sorvete tomou conta de cidade. Teve de aprender ali, o que não foi possível na infância. Vê-se, mais explicitamente, nesse exemplo, a estratégia de subjetivação acionada nesses filmes: apresentar 
cenas dos personagens cientistas, nas suas infâncias, em que eles eram muito diferentes dos/as outros/as para que certas crianças possam se reconhecer nas narrativas. Assim, não é apenas Flint que se identifica com o cientista experiente. No desenrolar das cenas, todas as crianças recebem o chamamento de juntarem-se ao seleto grupo de cientistas. Infantis não são as únicas produções demandadas nas animações. Uma subjetividade adulto-incentivadora é construída nas cenas descritas. São adultos/as que enxergam potencialidades em crianças com características diferenciadas; que sabem identificar a originalidade, a inteligência e a inventividade nos sujeitos tidos por todos/as como esquisitos; que procuram desenvolver estratégias que motivam e estimulam infantil-cientistas. Nos filmes analisados, a mãe de Flint e o Chester V correspondem a tal subjetividade. Tais personagens presenteiam com jaleco de cientista ou com colete laranja do inventor aqueles/as que recebem seus investimentos; apresentam a ciência como algo incrível, mas atingível, apesar de um empreendimento de esforços ser necessário; servem como referência nos momentos mais difíceis, em que seus pupilos pensam em desistir. São, sobretudo, modelos de subjetividades a serem seguidos pelos/as adultos/as telespectadores/as de modo a governá-los/as e a produzir comportamentos de incentivadores/as da ciência. Afinal, na medida em que visam certars subjetividades infantis, os filmes de animação "ensinam como os/as adultos/as devem se comportar a fim de conduzir os/as infantes e a si mesmos/as de forma correta (SILVA, 2010, p. 122).

Ao ser convocado a integrar a equipe do seu ídolo mesmo acreditando que seria por merecimento e longe de desconfiar das verdadeiras intenções -, Flint passa a conhecer o mundo da ciência profissional. Na Live Corp Corporations, "há quiosques de café a cada dez metros e adesivos de cafeína são distribuídos o dia inteiro", segundo a assistente primata. Aulas de yoga e esportes indoor são incentivados, mesmo que seus/suas participantes sejam vistos/as jogando com quase nenhuma habilidade. Além disso, pode-se apreciar o "telão da motivação", onde aparecem mensagens do "cientista maior", proferindo palavras de estímulo e excitação, quase como mantras de competição entre aqueles/as que ainda não alcançaram o tão sonhado colete laranja do Personalta dessa corporação. Ao chegar em seu espaço de trabalho, Flint vê-se em uma minúscula cabine, com computador e copo de café sobre uma mesa. A imagem panorâmica das inúmeras cabines como a dele assemelha-se a uma colmeia, em que, em cada compartimento, caberia apenas um/a cientista, apertadamente. Longe da ideia de coletividade da colmeia, no entanto, prioriza-se a individualidade e, consequente- 
mente, a competição entre aqueles/as que almejam destaque por meio de suas invenções que "mudariam o mundo". Flint, então, cria suas engenhocas simuladas em computador e as envia ao chefe. Seriam elas: "congelatador", "garfo e faca alimentador", "entregador de entrega" e "celebration". Mas, para seu desalento, em meio a uma plateia, predominantemente masculina de cientistas estagiários/as como ele, ávidos/as pelo resultado, descobre que nenhuma delas o fez ganhar o tão sonhado colete.

Cérebro ligado, cérebro sem ou com pouco corpo e cérebro superdotado é o que importa, em termos de corpo, para atuar na ciência. A oferta de cafeína, o reconhecimento de que cientistas não são afeitos/as aos esportes e a busca individualista pela melhor ideia dão indícios do que é considerado, nos filmes analisados, como importante a um/ a cientista. Todo pensamento formulado é tido, aqui, como fruto da maquinação cerebral. "Tira-se o papel das sensações, das percepções, do (resto do) corpo, e centraliza o ser pensante nesse órgão" (CARDOSO, 2012, p. 197). Evidenciase o privilégio do "polo imaterial do velho dualismo cartesiano, potencializando a mente e descartando o corpo como um meio obstáculo demasiadamente material" (SIBILIA, 2004, p. 205).

Além disso, no discurso científico divulgado, priorizar o cérebro é propor que o que faz ciência é a razão. Em nome de uma objetividade forjada, desde Galileu, cai-se em "um processo de descorporificação na ciência moderna", em que, às custas da eliminação do corpo, "se dá a universalidade da ciência" (GRÜN, 2007, p. 41). Seria a crença secular de que "a mente não só subjuga o corpo, mas nutre ocasionalmente a fantasia de fugir completamente à corporificação" (BUTLER, 2010a, p. 32). Uma crença que não é inventada nesse discurso científico moderno. A ideia de corpo como "matéria inerte que nada significa, ou, mais especificamente, significa o vazio profano, a condição decaída: engodo e pecado" (BUTLER, 2010a, p. 186) é fruto do discurso religioso. Em meio a tais chamamentos a certos modos de ser, Flint mostra-se completamente subjetivado. Diz que quer ser "vencedor igual ao Chester V", que é "como se ele falasse diretamente comigo com a linguagem da ciência", diz ele. Linguagem da ciência pode ser entendida, nos filmes analisados e de acordo com o discurso científico, como sendo toda a codificação gerada em laboratório e que propicia criar engenhocas tecnológicas. O laboratório é entendido, nos filmes, como o lugar "onde a mágica acontece", segundo Flint. Sobre ciência e cientista, contudo, Chester V adverte: "claro que não serão como eu, mas, lembrem-se: não há ciência pequena; há pequenos cientistas". Se há mau uso do laboratório ou o cientista não 
se empenha como deveria, a ciência pode parecer pequena. Na verdade, porém, o cientista é que não fez bom uso das ferramentas disponíveis e tornou a sua ciência limitada.

O discurso científico configura-se, então, como um operador que, ao mesmo tempo, concerne às coisas e aos homens (LATOUR, WOOLGAR, 1997). Ao passo que a experimentação surge como um dispositivo com a "função estratégica dominante" (FOUCAULT, 2007) de demarcar o que conta como ciência moderna, não mais medieval, um tipo de sujeito da experimentação é solicitado. Tal busca por "critério de demarcação" foi observada por Stengers (2000, p. 32), ao analisar como se dá essa definição. Conforme a autora, cientistas não se questionam "o que é ciência", mas, sim: "será que o que eu faço, ou o que vocês fazem é aceitável, é científico?" (STENGERS, 1990, p. 79). Assim, a ciência confere, a quem se diz cientista, a quem atende aos seus critérios de demarcação, "direitos e deveres" (STENGERS, 2000, p. 32). A partir daí, "um operador da experimentação, em suas práticas de laboratório, buscará, desde então, atender aos seus deveres - racionalidade, objetividade, empiria, ordenação, lógica - e saberá usufruir dos seus direitos de autoridade" (CARDOSO, 2012, p. 65).

Uma vez vestido do discurso científico, conduzindo suas subjetividades de modo para atender às demandas de uma classe, o sujeito científico-tecnológico assume um papel de autoridade frente aos outros saberes. Tal autoridade, por sua vez, confere-lhe a característica de dominação sobre o mundo, a natureza, a humanidade. Flint, personagem principal dos filmes em análise, é homem, branco, magro e de cabelos lisos. Chester $\mathrm{V}$, outro personagem de destaque e também representante da ciência, segue esse mesmo padrão corporal. Ambos são sujeitos com hábitos diferenciados, observadores, com inteligências notáveis e que sofreram rejeições em suas infâncias por possuírem tais características, que querem ser conhecidos mundialmente, que querem salvar a humanidade. Eles são o típico sujeito da ciência moderna, eurocêntrica e dominadora. Do mesmo modo, na pesquisa de Tomazi et al. (2009), os dados obtidos "permitem constatar que o principal estereótipo transmitido nos filmes de animação infantil é de um cientista homem, adulto, trajado casualmente e, na maioria das vezes, com jaleco, mesmo quando não está trabalhando em sua pesquisa" (2009, p. 302).

\section{Bonitinha e espertinha: a garota do tempol}

"Bonitinha e espertinha. Isso são requisitos para uma garota do tempo", sentencia o jornalista- chefe que, precisaria enviar repórter para cobrir a insignificante inauguração da 
Sardilândia, acerca da estagiária Sam Sparks. Após a sua desastrosa experiência jornalística ao vivo, seja pela troca das palavras, seja pelo atropelamento sofrido com a máquina eletrizada do Flint, Sam se isola em lamentos. Ao encontrar Flint e passar o primeiro estágio de brigas pela culpa que deposita nele pelo desastre, ela identifica suas invenções. Flint, então, apaixona-se pela sua inteligência, apesar do seu falatório e reclamações. "Queijos", "tomates", "alfaces", "molhos" e "carnes" caem do céu em TCH1 e interrompem esse encantamento! Surge "o maior fenômeno meteorológico de todos os tempos" e que, agora, seria coberto pela animada garota do tempo, Sam!

É necessário, no entanto, que uma nova chuva de comida seja produzida para que Sam possa aparecer novamente ao vivo e para que o prefeito ganhe notoriedade. Para isso, Flint precisa enfrentar o seu pai, que está à porta do laboratório dizendo que ele não deve fazer isso por não ser "algo natural". Após muitos argumentos, o filho só consegue convencê-lo quando diz baixo e timidamente: "é que... tem essa garota". Já no laboratório, Flint precisa reativar a máquina e, para ocupar Sam, coloca um "filme fofo" de um gatinho na internet que, por agradar tanto, foi visto por ela durante três horas seguidas. Flint consegue, a partir daí, reativar a máquina muitas vezes - para alívio do prefeito. Quando Flint já começa a enxergar problemas nas sucessivas chuvas de comidas, o prefeito usa seu sentimento por Sam, lembrandoo que isso também seria bom para impressionar a "cocadinha da Sam Sparks".

Bonitinha, espertinha, falante, conquistada, impressionável, fofa e cocadinha são os adjetivos atribuídos a mais nova assistente do Flint, o que faz apagar a sua inteligência. Tais atributos são tidos como típicos da doçura feminina: "qualidade mais importante da mulher" (CORAZZA, 2004, p. 285). Vê-se, aí, uma suposta essência feminina ser ativada para destinar o feminino a certas funções (PERROT, 2008) que, aqui, não seria o de papel principal na ciência. Em outras produções cinematográficas, a posição de mulher falante já foi identificada: "tagarelice e fofoca estão desde sempre relacionadas ao feminino, o que torna as mulheres agentes extraoficiais de notícias e novidades" (SABAT, 2002, p. 5).

Além disso, a heteronormatividade é acionada de maneira a posicionar homens e mulheres diferenciadamente: de um lado, o conquistador Flint; do outro, a conquistada Sam, o objeto de conquista. Isso fica igualmente evidente no início de TCH2, quando Flint ainda está excitado por terem acabado de "salvar o mundo" ao conter a máquina de comida. Ele, então, planeja: "um lugar só nosso: um laboratório!" e convida Sam. Ela, mais uma vez em sua posição de aquela que é conquistada, pronuncia o já 
conhecido "sim, sim, sim" com incontida felicidade, readaptando para cientistas a corriqueira cena de pedido de casamento. Nesse mesmo modo de entender a felicidade para uma mulher, os filmes se encerram com um beijo do casal heterossexual Flint e Sam, um discurso sexista de que "mulheres e homens são feitos um para o outro" (CORAZZA, 2004, p. 282). Em análises de filmes da Disney da década de 1990, Sabat argumenta que "independente do argumento central do roteiro, há início, meio e fim de um relacionamento amoroso, de um romance, com o clássico final feliz!" (2002, p. 2).

A heteronormatividade é uma "prática reguladora" que produz efeitos na "relação entre sexo, gênero, prática sexual e desejo", o que acaba por engendrar gêneros (BUTLER, 2010a, p. 39). Heteronormatividade entendida, ainda, como "regime da heterossexualidade [que] atua para circunscrever e contornar a 'materialidade' do sexo e essa 'materialidade' é formada e sustentada através de - e como - uma materialização de normas regulatórias que são, em parte, aquelas da hegemonia sexual" (BUTLER, 2010b, p. 170). Ao analisar o dispositivo da sexualidade, mais especificamente em sua construção do século XX, Foucault afirma que essa norma consistiu em "reduzir o sexo à sua função reprodutiva, à sua função heterossexual e adulta e à sua legitimidade matrimonial" (FOUCAULT, 2010, p. 114). Aos sabores desse conjunto de normas, quer-se uma identidade para um corpo e uma outra para outro corpo. Assim, em um sistema heteronormativo, caberiam, apenas, duas identidades de sexo/gênero/desejo: masculino e feminino.

Tal hipótese binária encerra "a crença numa relação mimética entre gênero e sexo, na qual o gênero reflete o sexo ou é por ele restrito" (BUTLER, 2010a, p. 24). Esses gêneros, no entanto, não diferem apenas pelo seu sexo, mas "por toda uma constituição física e moral" (CORBIN, 2008b, p. 185). Aqui, porém, prefiro entender que gêneros e sexualidades apontam "não para uma essência feminina ou masculina (natural, única ou mutável), mas para processos determinados e múltiplos de construção discursiva" (PARAísO, GONÇALVES, 2009, p. 03). Isto é, "gênero não pretende significar o mesmo que sexo" (LOURO, 1995b, p. 9). Para Butler (2010a), o sexo, o corpo sexuado é produzido cultural e discursivamente. Para ela, não há um sexo biológico e um gênero, que seria a construção social desse sexo biológico. O próprio sexo é cultural. Desse modo, as características generificadas destinadas à Sam são constructos culturais e, pelo contrário, não nasceram com ela. Do mesmo modo, o que é destinado aos homens também corresponde ao produto da cultura e não ao biológico, como os filmes insistiram em produzir com a ideia de que a 
inteligência, a inventividade e a conquista de Flint o acompanham desde sempre.

O personagem policial é mais um exemplo dessa posição dos filmes analisados. Ele faz a segurança da cidade no primeiro filme e da equipe de Flint no segundo. Nitidamente emocionado em uma cena, diz que a situação "é de fazer qualquer homem feito chorar, mas esse aqui não!", e faz a lágrima no canto do seu olho voltar. No final da segunda trama, ele não consegue segurar a tal lágrima. Quando ela cai sobre um dos espécimes de "comida viva", nasce cabelo em seu peito, tamanho é o nível de hormônios masculinos do policial. Em tal modo de construir personagens como o Flint e - Policial Earl, disponibiliza-se uma masculinidade socialmente aceita como conquistadora, "dura, forjada no esporte, na competição e numa violência consentida" (LOURO, 2010, p. 17). Nesse sentido há, ainda, o pai de Flint, com sua dificuldade de expressar seus sentimentos. $\mathrm{O} \mathrm{Sr}$. Lockwood's é construído como um sujeito durão, que não fala o que sente, que não se entende com o filho e que, por vezes, o reprime. Tudo isso é estabelecido em oposição à mãe emotiva, carinhosa e incentivadora, a Sra. Lockwood's. Apesar de Sam Sparks ser uma personagem exibida com inteligência e capacidade equiparadas com as de Flint, ela é apresentada, nos filmes, apenas como uma assistente, como uma subjetividade cientista-coadjuvante. A ela é dada uma função menor, apenas de acompanhar e ajudar o cientista. Em TCH1, quando Flint faz um sucesso inicial por conta da chuva de comidas, Sam tenta avisá-lo da formação de um tornado, mas é logo repreendida por ele, que pede que ela fique feliz por ele e que "vá cuidar da previsão do tempo, por favor". Relação semelhante é observada entre o Chester Ve sua assistente em TCH2. Bárbara, que prefere e exige ser chamada de primata, é uma macaca com cérebro humano. Ela é quem materializa os planos do chefe, sem nunca ser reconhecida por isso. No entanto, sempre que algo não acontece como deseja, Chester V a humilha e diz: "nunca peça para uma macaca fazer o trabalho de um homem". Assim, vê-se que homens e mulheres são posicionados/as de modos desiguais em relação à ciência. Enquanto um é afeito ao racional e à argumentação, a outra é destinada à função de ajudante, de tarefas manuais (CARDOSO, PARAÍSO, 2015).

A reiteração das normas não é observada apenas entre chefe e assistente. A própria Sam conta, em seu primeiro encontro com Flint, como sofreu por gostar do mundo da ciência em sua infância. Em suas palavras: "eu era uma nerd: rabo de cavalo, usava óculos e era obcecada por meteorologia. Enquanto as meninas queriam Barbie, eu queria um radar de tornados turbo. Fizeram uma música para me infernizar, então, mudei de visual, parei de me meter a ser 
cientista e pararam". Seus atos não se conformavam às normas de inteligibilidade cultural definida para garotas, devendo ser apresentada como "aquilo que não se deve ser, como um ser 'abjeto'” (CARVALHAR, 2009, p. 47). Por se sentirem autorizadas no "regime binário: lícito e não lícito, permitido e proibido" (FOUCAULT, 2010, p. 93), as normas punem "os que não desempenham corretamente o seu gênero" (BUTLER, 2010a, p. 199).

Sam viu-se entre distintos conjuntos de normas: o de gênero e o da ciência. Ao assumir, inicialmente, a composição de uma subjetividade cientista, foi necessário masculinizarse, adquirir características destinadas ao masculino. Posicionou-se, dessa forma, como "nerd", segundo ela mesma, regulando o seu corpo, cabelo, vestimentas e acessórios. $E$, ao considerar tal comportamento como incompatível ao gênero que se viu obrigada a assumir pelos/as seus/suas colegas, posteriormente, deixou de lado o seu interesse pela ciência e o seu visual. Desse modo, há, nos filmes analisados, o ensinamento de que a ciência é masculina, não combina com o feminino e, se se pretende fazer parte dela, é necessário masculinizar-se.

Assim, algumas características femininas tidas como naturais são classificadas como não compatíveis com o que é exigido no fazer científico. Se, em TCH1, era tida como tendo gosto por fofuras, em muitas cenas de TCH2 Sam ocupa o lugar daquela que desenvolve sentimento pelas "comidas vivas", mutações genéticas das primeiras comidas produzidas pela máquina de Flint em TCH1. É ela quem pede que o protagonista impeça o que seria a matança dessas novas espécies de seres, que se apega a alguns bichinhos enquanto todos integrantes da equipe estão alheios a isso, que acredita na inocência deles e que atrapalha os planos da ciência. Além das características atribuídas às mulheres já citadas, há, ainda, essa imagem de que a mulher é bondosa e altruísta. Em outro filme de animação, ao longo do desenrolar da narrativa, percebe-se que características como a beleza vão sendo desvalorizadas "em prol de outras características, como bondade e altruísmo, que são historicamente atribuídas e apreciadas nas mulheres", chegando-se à "verdadeira mulher" (SILVA, MAIA, 2014, p. 2).

Nos filmes analisados, portanto, mulheres são produzidas de modo a não possuírem a racionalidade e a objetividade solicitadas pelo discurso científico, apresentandose como emotivas e amorosas. Isso Ihes custa uma posição menor na ciência. De acordo com estudos sobre a mulher na ciência, "a maioria das mulheres participa do projeto na bancada do laboratório", enquanto os homens são os coordenadores (OSADA; COSTA, 2006, p. 294). Isto é, há uma segmentação das funções, "mantendo-as como técnicas e

474 Estudos Feministas, Florianópolis, 24(2): 463-484, maio-agosto/2016 
assistentes" (LOPES, 2006, p. 55), o que explicita a ideia de "incapacidade das mulheres serem boas pesquisadoras" (COSTA, 2006, p. 455) e as conduz a uma "ampla invisibilidade como sujeito - inclusive como sujeito da Ciência" (LOURO, 1997, p. 17). Ao analisar filmes de ficção científica da última década em busca das imagens construídas acerca dos cientistas, Cruz (2007) afirma que tal mídia contribui para a manutenção da imagem que contempla o cientista como um ser superior e do sexo masculino.

Além de posicionamentos diferenciados na ciência, haveria, ainda, certas ciências para umas e outros, com seus respectivos status, como se pode observar na discussão entre Bárbara e Sam quando a primeira tenta convencer Flint de que as "comidas vivas" de $\mathrm{TCH} 2$ são raivosas e perigosas para a humanidade, tese de seu chefe. Como Sam é persistente e não desiste de sua visão de ternura para esses espécimes, Bárbara pergunta, na tentativa de desmerecê-la: "por acaso é cientista?". Sam, desconcertada, diz que "na verdade, sim". Flint sai em sua defesa, afirmando que "ela é meteorologista". Bárbara, então, finaliza, irônica: "a ciência de sorrir com um penteado elegante, apontando para um mapa". Do mesmo modo, quando Chester V quer diminuí-la, chama-a de "aquela garotinha do tempo". Se alguns estudos comprovam que elas têm um papel secundário na ciência, outros mostram que não é em toda ciência que as mulheres estão presentes. A participação feminina só é maioria nas ciências humanas e linguísticas, sendo pequena nas ciências exatas (MELO; OLIVEIRA, 2006). Esses estudos apontam para a ideia de que, socialmente, a feminilidade é definida como apropriada apenas para algumas áreas do conhecimento.

\section{Salve-se quem puder!}

Se, quando criança, Flint desejava resolver o maior dos problemas de sua comunidade infantil - cadarços desamarrados -, agora, ele almeja ajudar sua cidade. Boca da Maré, uma ilha pesqueira, sempre foi conhecida pelas suas sardinhas, até que a fábrica local fechou, deixando toda a população com um enorme estoque desse gênero alimentício. Ao fazer chover hambúrgueres, ele acreditava estar realizando o seu sonho: "para uma cidade que é obrigada a se entupir de sardinha, isso aqui é um manjar dos deuses" (TCH1). Nota-se que o discurso científico que embala essas cenas move o cientista pelo problema, pela necessidade de uma resolução, pela busca de equacionar uma situação indesejada. O produto dessa busca científica são as tecnologias, artefato que mais expressa a visão utilitária que a ciência exerce sobre a natureza. Isso porque, na ciência, o valor e a importância do seu conhecimento 
são sempre medidas pela sua "eficácia prática" (JAPIASSU, 2007, p. 260).

Na subjetividade científico-tecnológica, é preciso adquirir uma visão mundial caso queira ser reconhecido e salvar a humanidade. Afinal, a atuação da ciência sobre as problemáticas tem alcances globais. Em diversas passagens, algum desastre mundial é projetado pelas personagens. "O tornado de comida está se formando para uma proporção mundial" (TCHI). "As comidas podem andar e atingir os continentes", invadindo todo o mundo (TCH2). Acreditando que a ciência pode impedir essas tragédias, Flint pede que seu pai se esforce para conseguir acessar seu e-mail no laboratório e enviar a senha da máquina, pois "o destino do mundo depende disso" (TCHI). Haveria, então, narrativas de salvacionismo em relação aos conhecimentos científicos e de dependência tecnológica. Isto é, uma concepção "de que a ciência e a tecnologia são capazes de resolver os problemas da humanidade" (FREIRE, 2007, p. 55).

Aquilo que é produzido pelas verdades científicas é apresentado à população como algo imprescindível, como necessário, como salvação. O cientista, por conseguinte, é construído como aquele que salva. O prefeito, por exemplo, chama Flint à responsabilidade: "o destino dessa cidade depende de você" (TCHI). Flint, por sua vez, sente-se um salvador: "o prefeito disse que vou cortar a fita, disse que eu salvei a cidade" (TCH1). Em outra situação, em que simulava o seu plano em computador, a última etapa está gravada em letras garrafais: "mundo salvo!" (TCH2). O próprio Chester $\checkmark$ aciona a estratégia de lembrá-lo do que é típico do cientista para que ele cumpra seus propósitos: "você precisa se concentrar em salvar o mundo; seja um herói" (TCH2). Nos momentos em que Flint e sua ciência estão em alta nas tramas, a população sempre aparece muito feliz. Ele está na posição de herói e, longe daquela imagem de excluído, recebe convites para almoço, inaugurações, entrevistas etc.

Salvador, globalizante e herói são demandas produzidas para sujeitos científico-tecnológicos bemsucedidos nesses filmes. Bem-sucedido significa não apenas produzir soluções para os problemas socioambientais da humanidade. Bem-sucedido é, também, obter o reconhecimento de outros cientistas. Flint, que, por vezes, atende a tais demandas, é um cientista que almeja inventar algo que impacte a humanidade e o torne famoso entre seus pares, que agrade, sobretudo, o seu ídolo, Chester V. Afinal, o conceito científico "nasce quando um operador está munido com a pretensão de ser legítimo em um campo determinado" (STENGERS, 1990, p. 75).

Ao produzir o cientista como herói, pinta-o com contornos de inocente, como se os efeitos de suas descobertas 
não pudessem ser previstos. O cientista é, então, apresentado com ares de inocência de alguém que não prevê os malefícios de sua invenção. Haveria, assim, aqui dois movimentos. O primeiro seria o de produzir a ciência e a tecnologia como algo benéfico apenas, aceitando-as sem problematizações. Exemplo dessa produção pode ser visto quando todos/as se entusiasmam com a chuva de comida, quando o pai de Flint é apresentado como alguém que parou no tempo - "comida tecnológica é demais para um velho como eu" -, quando as sentinelas, com suas roupas tecnológicas, vêm para substituir a força policial.

O segundo movimento corresponde à ideia de que o cientista não conseguiria mensurar os malefícios de suas ações. Em um diálogo entre Sam e Flint, em que ele responde à pergunta da moça sobre o que seria o "perigômetro", o cientista inventor afirma, com cara de inocente: "eu não sei [o que acontece quando a seta chega no amarelo ou vermelho]; isso nunca aconteceu" (TCH1). Quando as comidas passam a surgir cada vez maiores sob os efeitos da radiação constante, o próprio pai de Flint - aquele que é produzido nos filmes como um sujeito não afeito à ciência e à tecnologia - pergunta se está tudo sob controle, o que o faz duvidar de si mesmo, se saberia o que fazer com as mutações.

Tal suposta incapacidade de prever os malefícios vem associada à imagem de boas intenções que permeia o cientista. Ele age nos problemas, pensa na humanidade, prima pela ordem global, almeja o bem-estar social. Em TCH2, a equipe de Chester V, ao chegar na destruída ilha após o desastre das chuvas de comida de $\mathrm{TCH} 1$, apresenta-se com ares de "ajuda humanitária". Promete a limpeza geral, enquanto realocam a população para San Francisco. Porém, é apenas nas últimas cenas do segundo filme que entendemos as dimensões econômicas que envolvem as boas intenções da equipe de cientistas. As análises de Tomazi et al. acerca de filmes de ficção científica concluíram que "a ciência é vista somente como um instrumento para o bem comum" (TOMAZl et al., 2009, p. 304). Seria uma ideia de que o conhecimento é puro, sem ideologias e intencionalidades, cabendo o problema ao mau uso de algumas pessoas. Com isso, ignoram que a tecnologia "carrega as marcas, os interesses e características de sociedades ou de grupos hegemônicos em determinado momento histórico" (AULER, DELIZOICOV, 2006, p. 351). Nessa visão de ciência absoluta, "as certezas constituem-se de compreensões inclinadas para a tecnocracia não para a democracia. Certezas excluem decisões políticas, dificultam a participação democrática" (AULER, DELIZOICOV, 2006, p. 348).

Além de produzir o saber científico e seus produtos como bem intencionados e como benefícios para o bem- 
estar social, constrói-se a figura daqueles que não se reconhecem nesse saber e não acompanham os avanços tecnológicos. Seria, portanto, o sujeito outro da ciência e da tecnologia. Nos filmes analisados, tal figura é representada pelo pai do Flint. Um sujeito tido como atrasado, que não sabe utilizar tecnologias, que é inferiorizado. Essa subjetividade seria uma construção negativa da diferença, "por meio da exclusão ou marginalização daquelas pessoas que são definidas como 'outros'” (WOODWARD, 2008, p. 50). Estratégica e historicamente na mídia, "os grupos dominantes sempre falaram sobre os demais grupos e construíram representações que tiveram e têm efeitos de poder e de verdade" (PARAísO, 2004, p. 60). Na mídia analisada, o grupo de cientistas é classificado como superior em relação a não cientistas. Distanciar, diferenciar e separar significam, ainda, classificar. Isto é, "deter o privilégio de classificar significa também deter o privilégio de atribuir diferentes valores aos grupos assim classificados" (SILVA, 2008, p. 82).

Em tantos outros espaços, o método científico é operacionalizado para conferir e consolidar o saber científico moderno, derrubar teorias, promover alguns em detrimento de outros, produzir saberes e validar verdades (STENGERS, 2000; LATOUR, 2000). Nesse exercício, haveria uma prática de desqualificação daqueles/as que não se posicionam em tal sistema de racionalidade. Cardoso e Paraíso (2015), ao analisarem o currículo de aulas experimentais de ciências, afirmam que desqualificado para ciência é tudo aquilo que não é científico. Com isso, produz-se o sujeito desqualificado cientificamente, que seriam os não científicos, que

não explicam os acontecimentos por meio dos conhecimentos científicos, que possuem crenças religiosas ou crenças não testadas cientificamente, que são afeitos aos mitos e às lendas. É, ainda, um sujeito que não se baseia em fatos ou em verdades comprovadas, é o outro da ciência (CARDOSO, 2012, p. 223).

Os processos de subjetivação acionados nesses filmes de animação buscam não apenas produzir meninos e meninas científicos/as e tecnológicos/as. Eles se endereçam, também, ao papel da humanidade em geral, frente à sua dada dependência do conhecimento científico-tecnológico. Exemplo disso é quando Flint assume toda a culpa do desastre em TCH1. A grande maioria da população se revolta contra ele até ser interrompida pelo policial Earl: "Mas fomos nós quem pedimos e está na hora de todos pagarmos a conta!". A ideia de que ciência e tecnologia afetam a humanidade inteira produziria a necessidade de um constante debate em torno dos malefícios e benefícios advindos do progresso utilitário pela ciência. Segundo as análises realizadas por 
Bicca (2010, p. 238) em filmes de ficção científica, "os espectadores têm sido levados a identificarem-se com uma posição de cautela em relação aos perigos oferecidos pela tecnologia", fazendo-se um prognóstico de que não necessariamente a tecnologia tornará melhores as sociedades futuras e que todos precisam avaliar isso.

Essa seria, portanto, uma "tarefa não apenas para especialista, mas para todos os cidadãos - e especialmente para todos os professores de ciência, pela responsabilidade que têm na determinação das concepções que os alunos vêm a adotar" (OLIVEIRA, 1999, p. 191). A tarefa da educação científica seria, também, "desenvolver a autoconsciência crítica sobre o caráter da atividade científica e de suas aplicações e sobre as escolhas com as quais se defrontam seus participantes responsáveis" (LACEY, 1998, p. 139).

Assim, ao assistirem aos filmes aqui analisados, modos de subjetivação são direcionados às pessoas em geral, de forma a governá-las como sujeitos científico-tecnológicos, dependentes e usuários dos conhecimentos científicos e de seus produtos tecnológicos. Por conseguinte, são atravessados por enunciados de imprescindibilidade, de salvacionismo e de benefícios da ciência e da tecnologia. Assumem, a partir daí, um modo de vida em que estão garantidas as crenças em uma sociedade mais avançada, progressista, com maior qualidade e bem-estar social.

\section{Considerações finais}

Narrar a ciência e cientistas tem sido uma constante na sociedade ocidental. Dizer de suas descobertas, de suas importâncias, de seus impactos no cotidiano, tem ajudado a construir um conjunto de significados em torno desse grupo social. A esse respeito, revistas, telejornais e filmes, para os mais diversos públicos, têm atendido a tais propósitos. Nesse sentido, os filmes de animação aqui analisados estão imersos em uma cadeia discursiva ampla que tem definido como tem de ser, viver e portar-se o sujeito científico-tecnológico e como a humanidade em geral deve afastar-se do que não corresponde a isso. Longe de ser uma subjetividade préexistente ou natural para alguns, a subjetividade científicotecnológica tem recebido investimentos e tem circulado por diferentes espaços. Afinal, subjetividades, identidades e diferenças precisam "ser constantemente criadas e recriadas" (SILVA, 2008, p. 96).

Nas produções cinematográficas analisadas, nas mais diversas cenas e situações exibidas, homens e mulheres são produzidos/as com características essenciais específicas. Aos homens, caberiam a dominação, a conquista, a inteligência. Às mulheres, destina-se a beleza, a fofura, a delica- 
deza, a emoção, o sentimento, o amor. Tais características colocam-nos/nas em situações diferenciadas e desiguais em relação à ciência e à tecnologia. Por serem supostamente mais racionais, objetivos, dominadores, eles ganham o papel principal nas tramas científicas, mas, claro, se forem inteligentes, diferentes e malucos o bastante. O papel de assistência fica, então, com as mulheres. Isso contribui para a produção de sujeitos generificados na ciência com desigualdades de posições.

Nos artefatos culturais analisados, portanto, alguns sujeitos são próprios do fazer científico e tecnológico, do racional, da inventividade. Para identificar tais características nos sujeitos infantis, por um lado, subjetividades adultoincentivadoras são acionadas para que aqueles sujeitos possam desenvolver suas essências científicas e tornarem-se sujeitos infantil-científicos. Por outro lado, a subjetividade do outro da ciência e da tecnologia é construída de forma a negativar certo modo de existência que não se aproxima da ciência e da tecnologia. Nos filmes analisados, portanto, em meio a hambúrgueres, queijos e molhos, chovem discursos e demandas para o governo daqueles/as que os assistem.

\section{Referências}

AULER, Décio; DELIZOICOVI, Demétrio. "Ciência-TecnologiaSociedade: relações estabelecidas por professores de ciências". Revista Electrónica de Enseñanza de las Ciencias. v. 5, n. 2, 2006, p. 337-355.

BICCA, Angela D. N. Os filmes de ficção científica nos ensinando a viver em uma civilização cibernética. Tese (Doutorado), Programa de Pós-Graduação em Educação, Porto Alegre: UFRGS, 2010.

BUTLER, Judith. Problemas de gênero: feminismo e subversão da identidade. 3.ed. Rio de Janeiro: Civilização Brasileira, 2010a.

. "Corpos que pesam: sobre os limites discursivos do "sexo"”. In: LOURO, Guacira Lopes. O corpo educado: pedagogias da sexualidade. 3.ed. Belo Horizonte: Autêntica, 2010b, p. 151-172.

CÀMARA, Sergi. O Desenho Animado. Lisboa: Estampa, 2005.

CARDOSO, Lívia de R.; PARAISO, Marlucy Alves. "Dispositivo da experimentação e produção do sujeito homoexperimentalis em um currículo de ciências". Educação em Revista, v. 31, 2015. p. 299-320.

"Tecnologia de gênero e a produção de sujeitos no currículo de aulas experimentais de ciências". Currículo sem Fronteiras, v. 15, 2015, p. 155-177.

"Álbum fotográfico: um mapa de cenários discursivos na produção acadêmica brasileira sobre aulas experi- 
mentais de Ciências". Ciência \& Educação, v. 20, 2014, p. 83-115.

CARDOSO, Lívia de R. Homoexperimentalis: dispositivo da experimentação e tecnologias de subjetivação no currículo de aulas experimentais de ciências. Tese (Doutorado), Programa de Pós-Graduação em Educação, UFMG, 2012.

Conflitos de uma bruta flor: governo e quereres de gênero e sexualidade no currículo do fazer experimental. In: BRASIL. 70 Prêmio Construindo a lgualdade de Gênero. Brasília: Presidência da República, 2011 , p. 35-56.

CARVALHAR, Daniele Lameirinhas. Relações de gênero no currículo da educação infantil: a produção das identidades de princesas, heróis e sapos. Dissertação (Mestrado em Educação), Universidade Federal de Minas Gerais, 2009.

CORAZZA, Sandra. História da Infância sem fim. 2.ed. ljuí: Unijuí, 2004.

CORBIN, Alain. "O encontro dos corpos". In: CORBIN, Alain; COURTINE, Jean-Jacques; VIGARELLO, Georges. História do corpo: da Revolução à Grande Guerra. 2.ed. Petrópolis: Vozes, 2008b, p. 181-266.

COSTA, Amorim. "A procura e a descoberta da ordem e da desordem no Universo". In: GOLDFARB, Ana M. A.; BELTRAN, Maria H. R. (Orgs.). O saber fazer e seus saberes: experimentos, experiências e experimentações. São Paulo: Livraria da Física; EDUC; FAPESP, 2006, p. 253-284.

CRUZ, Joliane O. da. Mulher na ciência: representação ou ficção. Tese (Doutorado), Programa de Pós-Graduação em Ciências da Comunicação, São Paulo, USP, 2007.

DUARTE, Rosália. Cinema e Educação. Belo Horizonte: Autêntica, 2002.

FABRIS, Elí Henn. "Cinema e Educação: um caminho metodológico". Educação \& Realidade, Porto Alegre, v. 33, n. 1., jan-jun 2008, p. 117-134.

FOUCAULT, Michel. História da Sexualidade II. São Paulo: Graal, 2006.

A arqueologia do saber. Rio de Janeiro: Forense Universitária, 2005.

. As técnicas de si, 1982, p. 01-23. Disponível em: $<$ http://vsites.unb.br/fe/tef/filoesco/foucault/ tecnicas.pdf $>$.

."Nietzsche, a genealogia e a história". In: MACHADO, Roberto (Org.). Microfísica do Poder. 24.ed. Rio de Janeiro: Graal, 2007.

Do governo dos vivos. Curso no Collège de France, 1979-1980 (excertos). São Paulo: Centro de Cultura Social; Rio de Janeiro: Achiamé, 2010. 
FREIRE, L. I. F. Pensamento crítico, enfoque educacional CTS e o Ensino de Química. Dissertação (Mestrado), Programa de Pós-Graduação em Educação Científica e Tecnológica, Florianópolis, UFSC, 2007.

GIROUX, Henry A. "Memória e pedagogia no maravilhoso mundo da Disney". In: SILVA, Tomaz Tadeu da (Org.). Alienígenas na Sala de Aula. Uma introdução aos Estudos Culturais em Educação. Petrópolis: Vozes, 1995, p. 132-158.

GRÜN, Mauro. Em busca da dimensão ética da educação ambiental. Campinas: Papirus, 2007.

IGNÁCIO, Patrícia. Três Espiãs Demais ensinando um jeito de ser jovem menina. In: Fazendo Gênero 8 - Corpo, violência e poder. Florianópolis, 2008.

JAPIASSU, Hilton. Como nasceu a ciência moderna e as razões da filosofia. Rio de Janeiro: Imago, 2007.

KINDEL, Eunice A. I. A natureza no desenho animado ensinando sobre homem, mulher, raça, etnia e outras coisas mais... Tese (Doutorado), Programa de Pós-Graduação em Educação, UFRGS, Porto Alegre, 2003.

LACEY, Hugh. Valores e atividades científicas. São Paulo: Discurso Editorial, 1998. (Coleção Filosofia da Ciência e Epistemologia)

LATOUR, Bruno; WOOLGAR, Steve. A vida de laboratório: a produção dos fatos científicos. Rio de Janeiro: Relume Dumará, 1997.

. Jamais fomos modernos: ensaio de antropologia simétrica. $2^{a}$ reimpressão. Rio de Janeiro: Ed. 34, 2000.

LAURETIS, T. "A tecnologia do gênero". In: HOLLANDA, H. B. de. Tendências e impasses: o feminismo como crítica da cultura. Rio de Janeiro: Rocco, 1994.

LOPES, Maria Margaret. "Sobre convenções em torno de argumentos de autoridade". Cadernos Pagu. Campinas, jul-dez. 2006, p. 35-61.

LOURO, Guacira Lopes. "Nas redes do conceito de gênero". In: LOPES, Marta M.; MEYER, Dagmar; WALDOW, Vera R. (Orgs.). Gênero e Saúde. Porto Alegre: Artes Médicas, 1995, p. 7-17.

Gênero, Sexualidade e Educação: uma perspectiva pós-estruturalista. Petrópolis: Vozes, 1997.

. "O cinema como pedagogia". In: LOPES, Eliane; FARIA

FILHO, Luciano; VEIGA, Cynthia. 500 anos de educação no Brasil. Belo Horizonte: Autêntica, 2000, p. 423-446. . "Pedagogias da Sexualidade". In: LOURO, Guacira

Lopes (Org.). O corpo educado: pedagogias da sexualidade. 3.ed. Belo Horizonte: Autêntica, 2010.

MELO, Hildete Pereira; OLIVEIRA, André Barbosa. "A produção científica brasileira no feminino". Cadernos Pagu. Campinas, jul-dez. 2006, p. 301-331. 
OLIVEIRA, Marcos B. Da ciência cognitiva à dialética. São Paulo: Discurso Editorial, 1999. (Coleção Filosofia da Ciência e Epistemologia)

OSADA, Neide M.; COSTA, Maria. "A construção social de gênero na Biologia: preconceitos e obstáculos na biologia molecular". Cadernos Pagu. Campinas, jul-dez. 2006, p. 279-299.

PARAÍSO, Marlucy Alves. "Contribuições dos Estudos Culturais para a educação". Presença Pedagógica. v. 10, n. 55, Belo Horizonte, jan./fev. 2004, p. 53-61.

. "Política da subjetividade docente no currículo da mídia educativa brasileira". Educação e Sociedade. v. 27, n. 94. Campinas, 2006, p. 91-115.

Currículo e mídia educativa brasileira: poder, saber e subjetivação. Chapecó: Argos, 2007.

. "Apresentação". In: PARAísO, Marlucy Alves (Org.). Pesquisas sobre currículos e culturas: temas, embates, problemas e possibilidades. Curitiba: CRV, 2010, p. 11-14.

PARAÍSO, Marlucy Alves; GONÇALVES, Esfefa Pereira. A política curricular dos "reagrupamentos" escolares: práticas generificadas no currículo escolar. In: IV Colóquio Internacional de Políticas e Práticas Curriculares. João Pessoa, 2009.

PERROT, Michelle. Minha história das mulheres. São Paulo: Contexto, 2008.

SIBILIA, Paula. "O corpo obsoleto e as tiranias do upgrade". Verre, v. 6, 2004, p. 199-226.

SABAT, Ruth. Filmes infantis como máquinas de ensinar. In: Reunião Anual da Associação Nacional de Pós-Graduação e Pesquisa em Educação. GT Educação e Comunicação. Caxambu, 2002.

SILVA, Aline Marielle; MAIA, Cláudia de Jesus. Construindo a imagem da "verdadeira mulher" nas cenas de Deu a Louca na Branca. In: Fórum Ensino, Pesquisa, Extensão e Gestão. Unimontes, Belo Horizonte, 2014.

SILVA, Maria Carolina da; PARAíSO, Marlucy Alves. "A infância nos currículos de filmes de animação: poder, governo e subjetivação dos/as infantis". Revista e-Curriculum (PUCSP), v. 8, 2012, p. 1-19.

SILVA, Maria Carolina da. "Currículo de Filmes de Animação: poder, governo e subjetividade dos/as infantis". In: PARAíSO, Marlucy Alves (Org.). Pesquisas sobre currículos e culturas: temas, embates, problemas e possibilidades. Curitiba: CRV, 2010, p. 117-130.

SILVA, Tomaz Tadeu da. Documentos de identidade: uma introdução às teorias do currículo. Belo Horizonte: Autêntica, 2003.

"A produção social da identidade e da diferença". In: SILVA, Tomaz Tadeu da. Identidade e diferença: a 
perspectiva dos Estudos Culturais. Petrópolis: Vozes, 2008, p. 73-102.

STENGERS, Isabelle. As políticas da razão: dimensão social e autonomia da ciência. Lisboa: Edições 70, 2000. (Coleção O saber da Filosofia)

STENGERS, Isabelle. Quem tem medo da ciência? Ciências e poderes. São Paulo: Siciliano, 1990.

TOMAZI, Aline Luiza; PEREIRA, Aline Julyê; SCHÜLER, Cristiane Müller; PISKE, Karin; TOMIO, Daniela. "O que é e quem faz ciência? Imagens sobre a atividade científica divulgadas em filmes de animação infantil". Ensaio Pesquisa em Educação em Ciências, v. 11, n. 2. Belo Horizonte, dez. 2009, p. 292-306.

WOODWARD, Kathryn. "Identidade e diferença: uma introdução teórica e conceitual". In: SILVA, Tomaz Tadeu da. Identidade e diferença: a perspectiva dos Estudos Culturais. Petrópolis: Vozes, 2008, p. 1-72.

[Recebido em 12/10/2015

e aceito para publicação em 12/11/2015]

Relations of Gender, Science and Technology in the Curriculum of Animated Films Abstract: Inventions, technologies, experiments, books and tools are elements that are part of the plots of Cloudy with a Chance of Meatballs I and II. This article aims to analyze gender relations in such animated films that present the background and scientific inventions and technological truths permeated by gendered demands. Thus, I argue that, in the films analyzed, different subject positions for men and women are produced through the scientific-technological discourse. In the cultural artifacts analyzed, some subjects are part of the scientific doings, of the rational, of the technological inventiveness; others have secondary, supporting and assisting role. This contributes to the production of gendered subjects in science. Therefore, in the midst of hamburgers, cheese and sauces, many discourses and demands pour for the ones who watch them.

Keywords: Gender Relations; Scientific Discourse; Subjectivity.

484 Estudos Feministas, Florianópolis, 24(2): 463-484, maio-agosto/2016 